noticeable, however, that the author has confined his attention entirely to North American crops and conditions. Further, of the 522 references cited, only one derives from outside North America, and the same is true of the 393 tables in the book. The volume brings together much information which will be useful for elementary students of crop husbandry in North American agricultural colleges, but it is too parochial in outlook to interest more than a very few people in Great Britain.

W. B. BRIERLEY

\section{Dictionary of Genetics}

Including Terms used in Cytology, Animal Breeding and Evolution. Compiled by Dr. R. L. Knight. (Lotsya, a Biological Miscellany, Vol. 2.) Pp. xii 183. (Waltham, Mass. : Chronica Botanica Co. London: Wm. Dawson and Sons, Ltd., 1948.) 4.50 dollars.

7 HIS book contains, or attempts to contain, every It therefore spreads over (though it does not cover) the whole range of biology ; psychology and anatomy, embryology and biochemistry are all represented. It includes three thousand terms as compared with the five hundred in Darlington and Mather's recent glossary of the subject. Definitions are attempted; but there does not seem to be any standard or consistency in the use of alternative or related terms. Nor are there references or dates of origin; yet it is known, and it is worth relating, who invented such terms as gene and genotype. For some terms (such as cytomicrosome), the author proceeds by describing ignotum per ignotius; others (such as mitoschisis or merostathmokinesis) have never been used except by their anonymous inventors. Let us hope that others again (such as thermocleistogamy, tachyauxesis and spermiocalyptrotheca) never will be used. Others which have a known meaning lose it (such as "mass mutation" in CEnothera) or do not appear at all (such as "sterility"). Then again, others (such as heterofertilization or parthenogamy) describe rare or even imaginary phenomena. One supreme example which is non-existent as a technical term (perultimate chromomere) appears to be at once misplaced, misspelt and misdefined.

The majority of these terms, if they really existed, would be a reproach to biology; but I am happy to acknowledge that they are unknown to me. A dictionary of scientific terms may be a museum, or it may be a workshop. This book, however, is better described as a junk shop; and it may be that someone interested in words-even though not a student of the science of "thremmatology" or the theory of the "Genorheithrum"-will turn over its glittering and unauthentic fragments with the fascination of the collector looking for a gem brighter and more improbable than all the rest.

\section{D. Darhington}

Twelve Lectures on Theoretical Rheology By Prof. Markus Reiner. Pp. 163. (Amsterdam : North-Holland Publishing Co.; New York: Interscience Publishers, Inc., 1949.) $9 \mathrm{f}$.

A LTHOUGH rheology is a branch of physics, A many of those concerned with its practice were trained in chemistry or in other sciences, and are unfemiliar with the tensor theory and notation which so greatly simplifies the treatment of its fundamental principles. Prof. Markus Reiner's earlier "Ten Lectures" will be remembered by many as their first introduction to the use of tensors in rheology.
Unfortunately, the number of copies of the earlier edition which reached Great Britain was limited; moreover, the printing, undertaken by those who were clearly unfamiliar with Latin script, left much to be desired. The enlarged new edition, "Twelve Lectures", remedies these defects, being excellently produced. There are also certain improvements and simplifications in the tensor treatment, as well as a number of useful additions.

As a companion volume to Prof. Reiner's "Deformation and Flow", this book is to be highly recommended. The author is a born teacher and has a quite unusual capacity for foreseeing where the reader's main difficulties are likely to arise. Thus, although much of the subject-matter is to be found in older and larger text-books, rheologists, especially those who have lost their youthful capacity for digesting the works of Love or Lamb, will welcome this far simpler presentation.

The author points out that "the treatment is phenomenological and does not take account of the discrete 'atomistic' structure of matter and its dynamical (kinetic) theory". This is a welcome reaction to the prevalent tendency to regard the 'atomistic' approach as the only legitimate line in physics.

G. W. S. B.

\section{New Developments in Ferromagnetic Materials}

With Introductory Chapters on the Statics and the Dynamics of Ferromagnetism. By J. I. Snoek. Second revised and enlarged edition. Pp, viii +139. (Amsterdam and New York: Elsevier Publishing Co., Inc.; London: Cleaver-Hume Press, Ltd., 1949.) 15s. $T \mathrm{~T}$ is only fair to state that, while one is glad to 1 welcome a second edition of Dr. J. L. Snoek's most valuable little book, it contains practically no new material. In fact, the additions or enlargements consist only of three pages of notes, mainly on ferromagnetic absorption and dispersion at high frequencies, added to the original appendixes. This is a pity, for one cannot imagine, for example, that the Dutch have lost all interest in ferrites; and all of us interested in the theory and experiment of magnetization processes would have liked to learn more of their recent work, particularly in view of the note in italics on p. 67 of each edition. $\quad$ L. F. B.

The Works of George Berkeley, Bishop of Cloyne Edited by A. A. Luce and T. E. Jessop. (Bibliotheca Britannica Philosophica.) Vol. 3: Alciphron or The Minute Philosopher. Edited by T. E. Jessop. Pp. $v+338$. (London and Edinburgh: Thomas Nelson and Sons, Ltd., 1950.) 30s. net.

THIS volume of the new edition of Berkeley contains one work only, the longest of his books and the most perfect in literary form. It is one of the liveliest and finest philosophical dialogues in English, or perhaps in any language; but it contains practically nothing of Berkeley's own philosophy. As stated on the title page, it is "An apology for the Christian religion against those who are called Freethinkers". Berkeley is attacking, not so much the theories of writers of learned books, as the fashionable paganism of the 'bright young people' of the 1720 's, who resembled those of the 1920's in eagerly picking up philosophical or quasi-philosophical arguments out of the learned books in order to justify their vices and frivolities. "Alciphron" was the most popular of Berkeley's books in his own day and bears the passage of time better than such controversial works usually do. $\quad$ A. D. R. 